\title{
Correction to: ABCA7 and EphA1 Genes Polymorphisms in Late-Onset Alzheimer's Disease
}

\author{
Mahnaz Talebi $^{1}$ - Azra Delpak ${ }^{1} \cdot$ Mohamad Khalaj-kondori $^{2} \cdot$ Saeed Sadigh-Eteghad ${ }^{1} \cdot$ Malihe Talebi $^{3}$. \\ Elham Mehdizadeh ${ }^{1} \cdot$ Alireza Majdi $^{1}$
}

Published online: 10 December 2019

(C) Springer Science+Business Media, LLC, part of Springer Nature 2019

\section{Correction to: J Mol Neurosci (2019)}

https://doi.org/10.1007/s12031-019-01420-x

The original version of this article unfortunately contained a mistake in the Authorgroup section. Author Azra Delpak's given name was misspelled as "Azar".

The original article has been corrected.

The online version of the original article can be found at https://doi.org/ 10.1007/s12031-019-01420-x

Alireza Majdi alimaj1992@yahoo.com; majdiar@tbzmed.ac.ir

1 Neurosciences Research Center (NSRC), Tabriz University of Medical Sciences, Tabriz, Iran

2 Department of Biology, Faculty of Natural Science, University of Tabriz, Tabriz, Iran

3 Health Center of East Azerbaijan Province, Tabriz, Iran 